Article

\title{
The Urban Transition Performance of Resource-Based Cities in Northeast China
}

\author{
Juntao Tan ${ }^{1,2}$, Pingyu Zhang ${ }^{1, *}$, Kevin Lo $^{3}$, Jing Li ${ }^{1}$ and Shiwei Liu ${ }^{1}$ \\ 1 Northeast Institute of Geography and Agroecology, Chinese Academy of Sciences, \\ Changchun 130002, China; tanjuntao@iga.ac.cn (J.T.); lijingsara@iga.ac.cn (J.L.); liushiwei@iga.ac.cn (S.L.) \\ 2 University of Chinese Academy of Sciences, Beijing 100049, China \\ 3 Department of Geography, Hong Kong Baptist University, Hong Kong, China; lokevin@hkbu.edu.hk \\ * Correspondence: zhangpy@iga.ac.cn; Tel.: +86-431-8554-2301; Fax: +86-431-8554-2298
}

Academic Editors: Patricia Romero-Lankao, Olga Wilhelmi and Mary Hayden

Received: 21 July 2016; Accepted: 29 September 2016; Published: 13 October 2016

\begin{abstract}
Resource-based cities face unique challenges when undergoing urban transitions because their non-renewable resources will eventually be exhausted. In this article, we introduce a new method of evaluating the urban transition performance of resource-based cities from economic, social and eco-environmental perspectives. A total of 19 resource-based cities in Northeast China are studied from 2003 to 2012. The results show that resource-based cities in Jilin and Liaoning provinces performed better than those in Heilongjiang province. Liaoyuan, Songyuan and Baishan were ranked as the top three resource-based cities; and Jixi, Yichun and Heihe were ranked last. Multi-resource and petroleum resource-based cities performed better than coal and forestry resource-based cities. We also analyzed the factors influencing urban transition performance using the method of the geographic detector. We found that capital input, road density and location advantage had the greatest effects on urban transition performance, followed by urban scale, remaining resources and the level of sustainable development; supporting policies and labor input had the smallest effects. Based on these insights, we have formulated several recommendations to facilitate urban transitions in China's resource-based cities.
\end{abstract}

Keywords: resource-based cities; urban transition; assessment of performance; old industrial base in Northeast China

\section{Introduction}

Resource-based cities are cities in which development depends primarily on the exploitation and primary processing of natural resources (e.g., minerals, energy and virgin forests). Because these natural resources are typically non-renewable, a resource-based city's economy inevitably proceeds through a process of exploration, exploitation, high yield and ultimately exhaustion [1], and this process has a huge effect on the overall transitions of resource-based cities. In the long run, resource-based cities have little room for economic improvement if they do not restructure their industries and develop a non-extractive economy [2]. Furthermore, the high unemployment, single employment structure, low social security, ecological deterioration and other social and eco-environment problems also need solving. Additionally, once a city exhausts its resources and the economy contracts, various serious problems would be exacerbated, such as stagnation of economic development, living standards dropping sharply and ecological environment deterioration (such as Fuxin before 2000). The transition of resource-based cities is a subject of global interest. Several resource-based cities and regions, such as Pittsburgh, Houston and the Ruhr area, have already transitioned to post-industrial models of development, and learning from these overseas experiences is invaluable for China's resource-based cities. The Ruhr area was a center of coal and steel production since the mid-19th century. However, 
the area faced structural crisis because of a decline in coal demand since the late 1950s. After decades of transformation, the Ruhr has become a "Helicon Valley" because of its leadership in alternative energy research, e-commerce and software development and is among the world's most successful restructured industrial regions [2]. Furthermore, the government tried out various strategies to effectively improve the ecological environment, brown field redevelopment and cultural heritage. When the People's Republic of China was established in 1949, a large number of resource-based cities, such as Daqing, Panzhihua, Qitaihe and Yichun, were developed to meet the needs of large-scale industrialization, and they flourished under the planned economy [3]. However, with the implementation of the reform and opening-up policy and the depletion of natural resources, some inherent problems began to emerge during the post-1978 reform period [1]. In the 1980s, a recession occurred in China's many resource-based cities, and economic difficulties persisted and grew in magnitude through the early 2000s, with a large number of state-owned resource enterprises going bankrupt [2,4]. As a result, the Chinese government began taking measures to revive resource-based cities. In 2001, Fuxin, a coal town in the northeast, was chosen to undergo an economic transition as an experimental resource-based city. In October 2003, a policy titled Opinions on the Strategy of the Revitalization of Northeast China and Other Old Industrial Bases was promulgated by the State Council. The document provided specific guidance for the transition of different types of resource-based cities and the transition in resource-based cities fully implemented. The cities with abundant resources should strengthen the deep processing and comprehensive utilization of resources and extend the industrial chain. The cities with declining resources should consider the problem of alternative industries, and the cities with depletion of resources and close to exhaustion should accelerate the development of continuous industry. Furthermore, the cities should speed up environment restoration and pollution control in mining areas and solve the problems of reemployment for workers and the closure and bankruptcy of mining enterprises. In 2008, 2009 and 2012, three groups of cities (69 cities in total) were designated as resource-exhausted cities (counties, districts), and Liaoning, Jilin and Heilongjiang province accounted for 20 of these cities. There are a number of resource-based cities in Northeast China that produced a wealth of mineral and timber resources in the past. However, their resources are now severely depleted, and an urban transition for a better economic structure, living standards and ecological environment is urgently needed. By 2012, the urban transition of resource-based cities in Northeast China had been fully implemented over a decade.

Transition is considered as a societal process of fundamental change in culture, structure and practice [5]. The scholarship on urban transitions has mainly applied the transition conceptual models in urban context [6]. The compact city, smart growth, eco-city, low-carbon city, creative city, living city, smart city and various ideas, to some extent, all contain urban transition characteristics [7]. Sustainable urban transition refers to structural transition processes, multi-dimensional and radical change, that can effectively direct urban development towards ambitious sustainability goals [8]. The early stages of urban transition drew substantial attention of researchers in urban economics [9]. Additionally, now, the research of urban transition mainly includes institutional transition (democratic government elections, privatization, price liberalization, foreign trade liberalization), social transition (internationalization, economic restructuring, social polarization, postmodern culture, neo-liberal politics) and reconfiguring the urban landscape (city center commercialization, inner city regeneration, outer city suburbanization) [10].

Resource-based cities as a special type of city have become the hot area of research. The research of resource-based cities originated in the 1930s, which was marked by Canadian geographer H.A. Innis [11]. Substantial research on resource-based cities has been conducted, including the causes and mechanisms of the problems of resource-based cities [12]; the impact of transition on a resource-based city's economic development, labor market and community development [13,14]; the social development of resource-based cities [15]; resource-based cities' urban efficiency [16]; and the effect of government policy on urban transition $[17,18]$. Since the late 20th century, the sustainable development discourse has become hegemonic in the field of resource-based cities, and the sustainable development of resource-based cities has become an important issue [19]. From this perspective, 
scholars have researched the frameworks and analytical methods that are applicable to resource-based cities and industries [20,21], and they have endeavored to establish the indicators of sustainable development. Some empirical research from various regional scales has been performed. Yu et al. measured the sustainability of China's major mining cities and contrasted them with other types of cities [22]. Wang et al. and Dong et al. researched the sustainable development of resource-based cities in China at the provincial level and individual city level, respectively [23,24]. In addition, the factors influencing the sustainable development of resource-based cities, including levels of economic development, industrial structure, technological progress, export dependence, city size and urban type, have been studied [25]. Until recently, there had been abundant research on resource-based cities' transition and sustainable development, but there had been little empirical research on evaluating the performance of resource-based cities that had undergone transitions, with the notable exception of Yu et al. [26,27]. While the method in the study of Yu et al. was using the growth rate of detailed indicators, what is absent in the literature is a systematic approach to comparing and linking the transition performance and its mechanisms for resource-based cities. This article develops a sustainable development capability evaluation index system to evaluate the urban transition performance systematically.

Before proceeding any further, the word "performance" should be clarified. Performance is often used in the field of management to indicate meaning the degree to which the results obtained by an individual, a team or an organization engaging in an activity are satisfactory [28,29]. The transition of resource-based cities typically focuses on economic restructuring by reducing the city's dependence on its resource-based industries, which will have a knock-on and positive effect on living standards, social stability and the environment [30]. Therefore, we broadly define the transition performance of a resource-based city as the economic, social and eco-environmental achievements of the city after it undergoes urban transition. Conceptually, transition performance consists of three components: (1) economic transition performance; (2) social transition performance; and (3) eco-environmental transition performance. Economic transition performance focuses on industrial restructuring, economic output, government revenue, government expenditure, etc. Social transition performance looks at resident income, unemployment, education and healthcare. Eco-environmental performance mainly refers to investments in environmental protection, energy consumption efficiency and the discharge of pollutants.

Following this definition, this article develops a sustainable development capability evaluation index system to evaluate the urban transition performance of resource-based cities in Northeast China. We focused on Northeast China because, as a region with a high concentration of resource-based cities, the urban transition and sustainable development of resource-based cities are the key factors revitalizing the flagging economy of this region [31]. Since the initiation of the revitalization strategy in 2003, the government has provided strong political and financial support for the transition of resource-based cities in Northeast China. Because urban transition efforts have been implemented in the Northeast for over a decade, the region provides good data for us to evaluate the urban transition performance of resource-based cities, explore a variety of mechanisms and provide guidance for further efforts.

\section{Study Area and Research Methods}

\subsection{Study Area}

Northeast China officially includes the provinces of Liaoning, Jilin and Heilongjiang, as well as the eastern part of Inner Mongolia. Because Liaoning, Jilin and Heilongjiang are commonly considered to be the core of Northeast China, this article only focuses on the resource-based cities in these regions. There are 21 resource-based cities (prefecture-level) in the study area: 6 in Liaoning (Panjin, Anshan, Benxi, Huludao, Fushun and Fuxin), 6 in Jilin (Songyuan, Jilin, Liaoyuan, Baishan, Tonghua and Yanbian Korean Autonomous Prefecture) and 9 in Heilongjiang (Mudanjiang, Jixi, Qitaihe, Hegang, Yichun, Daqing, Shuangyashan, Heihe, Daxinganling) (Figure 1). Because of data limitations, 
we excluded two cases: Daxinganling and Yanbian Korean Autonomous Prefecture. The remaining 19 resource-based cities accounted for $53.7 \%$ of the total land area of the region and $35.5 \%$ of the total population. These cities accounted for $41.4 \%$ of the regional GDP, and the per capita GDP was 53,610 Yuan in 2012, which is higher than the average for Northeast China at 46,001 Yuan. Reserves of oil, coal and iron ore accounted for $25.62 \%, 5.3 \%$ and $30.4 \%$ of the national total in 2012 , respectively. In brief, there are a number of resource-based cities in Northeast China that produced a wealth of mineral and timber resources in the past. However, their resources are now severely depleted, and an urban transition for a better economic structure, living standards and ecological environment is urgently needed.

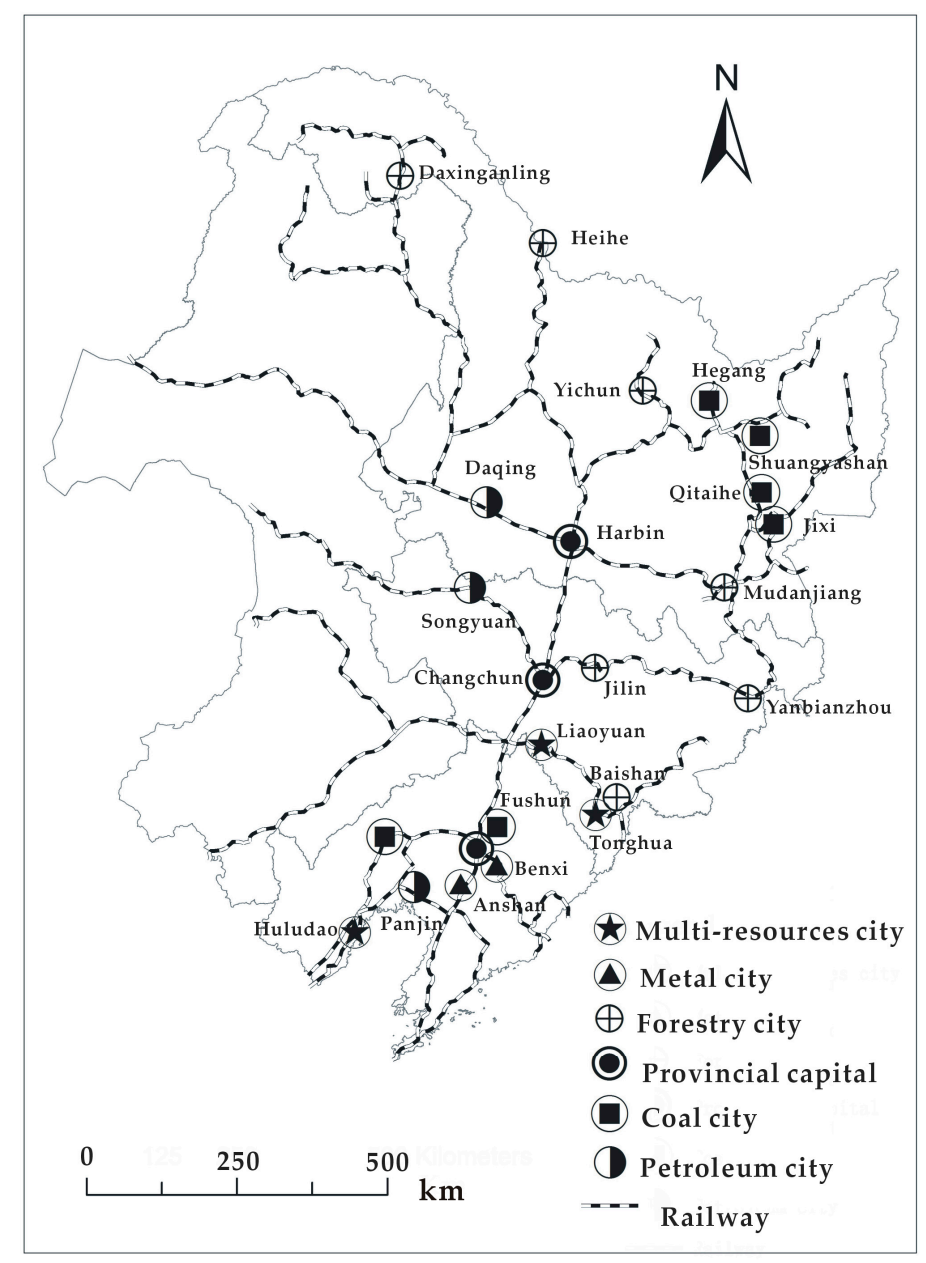

Figure 1. Spatial distribution of the main resource-based cities in Northeast China.

Since the implementation of the revitalization strategy in 2003, resource-based cities in Northeast China have had some achievements in their urban transitions. Fuxin was designed to be the first experimental mining city to undergo economic transition in 2001. Daqing, Yichun, Liaoyuan, Baishan and Panjin were designated as experimental resource-based cities for economic transition in 2007. The reforms and restructuring of state-owned enterprises achieved some remarkable results. The number of employees in state-owned and collective-owned units was 3.26 million in 2012, a decrease of 988,600 compared to 2003 , and the share of the economy held privately increased significantly. The social security system also improved gradually, and the number of unemployed people declined. In 2003, the number of registered unemployed persons was 418,700 , which later dropped to 351,000 in 2012. Living standards and the urban environment improved significantly. Power consumption and pollutant emissions per GDP decreased, whereas green areas in municipal districts increased rapidly, from $479 \mathrm{~km}^{2}$ in 2003 to $802 \mathrm{~km}^{2}$ in 2012. However, there were still many 
institutional and structural contradictions in resource-based cities. New industries developed slowly, and the area was characterized by a brain drain and a lack of long-term mechanisms to promote sustainable development.

\subsection{Methodology}

We employed a four-step research design as follows. Step 1 involved developing a theoretical framework. Because the ultimate goal of the transition of resource-based cities is to achieve sustainable development, we develop the concept of sustainability to evaluate the urban transition performance of resource-based cities. Early examples of sustainability assessment indexes include sustainable economic welfare, ecosystem well-being, human well-being and ecological footprint [22]. In 1997, the Global Reporting Initiative (GRI) was launched with the goal of "enhancing the quality, rigor and utility of sustainability reporting". The GRI uses a hierarchical framework in three focus areas: social, economic and environmental [32]. Later studies have adapted the GRI by adding other indicators to suit different local contexts and needs in assessing sustainability [33,34]. Sustainability indicators have become the most commonly-accepted approach to assessing sustainable development precisely because they are flexible enough to bring different meanings to different situations [35]. In a mining context, Azapagic and Yu et al. developed frameworks for sustainability indicators consisting of economic, environmental, social and integrated indicators [29]. We further developed the sustainable development capability evaluation index based on social, economic and environmental aspects including 24 indicators (Table 1). Data from 2003 to 2012 were used to evaluate urban transition performance, and the overall value of urban transition performance is the sum of economic, social and eco-environmental transition scores.

Table 1. Sustainable development capability evaluation index system of resource-based cities.

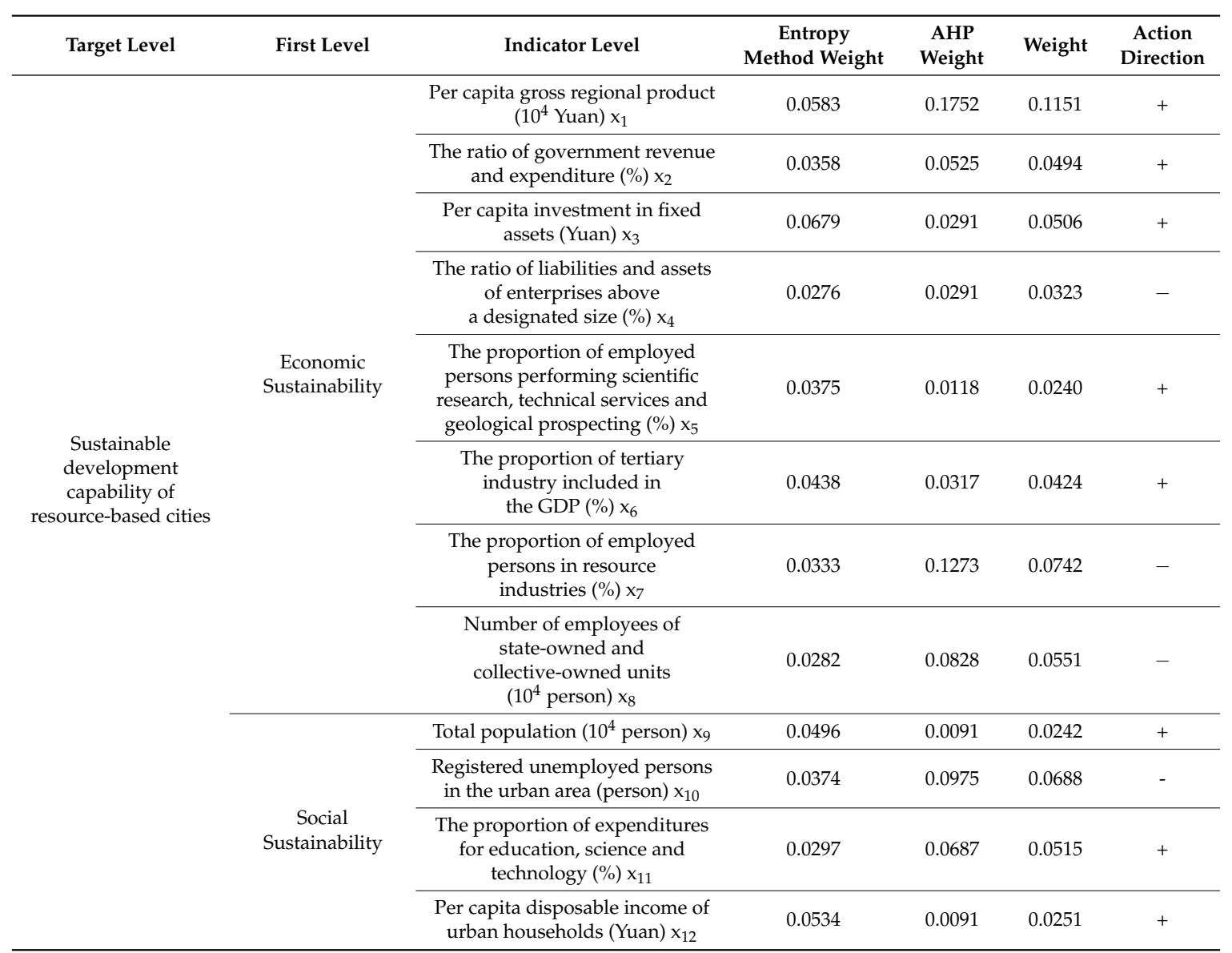


Table 1. Cont.

\begin{tabular}{|c|c|c|c|c|c|c|}
\hline Target Level & First Level & Indicator Level & $\begin{array}{l}\text { Entropy } \\
\text { Method Weight }\end{array}$ & $\begin{array}{c}\text { AHP } \\
\text { Weight }\end{array}$ & Weight & $\begin{array}{c}\text { Action } \\
\text { Direction }\end{array}$ \\
\hline \multirow{8}{*}{$\begin{array}{c}\text { Sustainable } \\
\text { development } \\
\text { capability of } \\
\text { resource-based cities }\end{array}$} & \multirow{3}{*}{$\begin{array}{c}\text { Social } \\
\text { Sustainability }\end{array}$} & $\begin{array}{l}\text { Number of higher education } \\
\text { students per } 10,000 \text { people } \\
\text { (person) } x_{13}\end{array}$ & 0.0402 & 0.0138 & 0.0268 & + \\
\hline & & $\begin{array}{l}\text { Number of beds in healthcare } \\
\text { institutions per } 10,000 \text { people } \\
\text { (bed) } x_{14}\end{array}$ & 0.0454 & 0.0208 & 0.0350 & + \\
\hline & & $\begin{array}{c}\text { Per capita total retail sales of } \\
\text { social consumer goods (Yuan) } x_{16}\end{array}$ & 0.0267 & 0.0313 & 0.0330 & + \\
\hline & \multirow{5}{*}{$\begin{array}{l}\text { Eco-environmental } \\
\text { Sustainability }\end{array}$} & $\begin{array}{c}\text { The ratio of land used for urban } \\
\text { construction and urban } \\
\text { areas }(\%) x_{17}\end{array}$ & 0.0262 & 0.0114 & 0.0197 & + \\
\hline & & $\begin{array}{l}\text { The consumption of electricity } \\
\text { per industrial output } \\
\left(\mathrm{kW} \cdot \mathrm{h} / 10^{4} \text { Yuan) } \mathrm{x}_{19}\right.\end{array}$ & 0.0205 & 0.0258 & 0.0262 & - \\
\hline & & $\begin{array}{l}\text { Water supply per capita in the } \\
\text { urban area (ton) } x_{20}\end{array}$ & 0.0483 & 0.0172 & 0.0328 & + \\
\hline & & $\begin{array}{c}\text { Forest coverage rate in the } \\
\text { urban area }(\%) x_{21}\end{array}$ & 0.0337 & 0.0536 & 0.0484 & + \\
\hline & & $\begin{array}{l}\text { Industrial waste water } \\
\text { discharged }\left(10^{4} \text { ton }\right) x_{22}\end{array}$ & 0.0377 & 0.005 & 0.0156 & - \\
\hline
\end{tabular}

Note: The resource industries in the indicator "The proportion of employed persons of resource industries" refer to forestry and mining industries. The emission index of waste water, gas and solid wastes per 10,000 GDP refers to the sum of standardized industrial waste water, industrial dust and $\mathrm{SO}_{2}$.

In Step 2, we conducted the urban transition performance assessment. First, to avoid the difficulties caused by different dimensions and orders of magnitude, the raw data were normalized and calculated as follows with Equation (1).

$$
\mathrm{x}_{\mathrm{ij}}^{\prime}=\left\{\begin{array}{l}
\left(\mathrm{x}_{\mathrm{ij}}-\mathrm{x}_{\mathrm{j}} \min \right) /\left(\mathrm{x}_{\mathrm{j}} \max -\mathrm{x}_{\mathrm{j}} \min \right) ; \text { when } \mathrm{x}_{\mathrm{ij}} \text { is positive indicator } \\
\left(\mathrm{x}_{\mathrm{j}} \max -\mathrm{x}_{\mathrm{ij}}\right) /\left(\mathrm{x}_{\mathrm{j}} \max -\mathrm{x}_{\mathrm{j}} \min \right) ; \text { when } \mathrm{x}_{\mathrm{ij}} \text { isnegative indacator }
\end{array}\right.
$$

where $x_{i j}$ is the original index; and $x_{j}$ max and $x_{j}$ min are the maximum and minimum values of the $\mathrm{j}$ indicator, respectively. After normalization processing, all of the index values are in the 0 to 1 range.

Second, to decide on the weights of different indicators, we used a subjective evaluation method (analytic hierarchy process (AHP)) and an objective evaluation method (entropy method), and the results were $w_{1 j}$ and $w_{2 j}$. AHP is a structural technique for dealing with complex decisions. AHP offers a framework for structuring a decision problem, quantifying its elements and evaluating alternative solutions [36]. We used AHP to determine the indicator weights of three subsystems (Table 1). Entropy is used to measure uncertainty in information. The larger the amount of information, the smaller the uncertainty and entropy are, and vice versa [36]. The equation of the original data matrix is $X=\left(x_{i j}\right)_{m \times n}$, where $x_{i j}$ represents the value of the $i$-th sample assigned to the $j$-th evaluation index, and the $\mathrm{m}, \mathrm{n}$ represents the number of study samples and indicators. The steps of the estimation are as follows [37-39]:

(1) Formation of standardization matrix with Equation (2).

$$
\mathrm{Y}=\left(\mathrm{Y}_{\mathrm{ij}}\right)_{\mathrm{m} \times \mathrm{n}^{\prime}} \mathrm{y}_{\mathrm{ij}}=\left(\mathrm{x}_{\mathrm{ij}}\right) / \sum_{\mathrm{i}=1}^{\mathrm{m}} \mathrm{x}_{\mathrm{ij}}
$$


(2) Calculation of the entropy of the j-th index with Equation (3).

$$
\mathrm{e}_{\mathrm{j}}=-\mathrm{k} \sum_{\mathrm{i}=1}^{\mathrm{m}} \mathrm{y}_{\mathrm{ij}} \ln \mathrm{y}_{\mathrm{ij}}, \mathrm{k}=(\operatorname{lnm})^{-1}
$$

(3) Calculation of the coefficient of variance of the $j$-th index with Equation (4).

$$
\mathrm{h}_{\mathrm{j}}=1-\mathrm{e}_{\mathrm{j}}
$$

(4) Calculation of the weight of the j-th index with Equation (5).

$$
w_{2 j}=h_{j} / \sum_{j=1}^{n} h_{j}
$$

Based on the minimum relative entropy principle [40], the comprehensive weight was $\mathrm{w}_{\mathrm{j}}$, and calculated with Equation (6).

$$
w_{j}=\sqrt{w_{1 j} \times j_{2 j}} / \sum_{j}^{m} \sqrt{w_{1 j} \times j_{2 j}}
$$

Finally, we calculated the performance of each city $\left(\mathrm{z}_{\mathrm{j}}\right)$ with Equation $(7)$.

$$
\mathrm{z}_{\mathrm{j}}=\mathrm{w}_{\mathrm{j}} \times \mathrm{x}_{\mathrm{ij}}^{\prime}
$$

Using the same method, we could calculate economic, social and eco-environmental transition performance, and the score for urban transition performance is the sum of these three aspects.

In Step 3, we carried out the influential factors analysis. We used the method of the geographic detector to analyze the factors that influence urban transition performance. The geographic detector method was initially applied to study endemic diseases and the relevant geographic risk factors [41], but it has since been applied to the study of urbanization, economic growth and other economic and social areas. Compared with conventional statistical methods, the geographic detector model is less restricted by hypotheses [42]. Factor detectors are used to examine whether an environmental factor is the reason for the spatial pattern. If influential factors and the change in geographic objects have a significant spatial correlation, this indicates that influential factors have decisive significance for the occurrence and development of geographical objects [41,43].

Assuming the transition performance of resource-based cities is $U$ and the number of resource-based cities is $n$, the influential factor for urban transition performance is $D=\left\{D_{i}\right\}$ (i denoting the number of classifications, and the total number of classifications is $\mathrm{m}$; in this article, we classified the influential each factor into 4 classifications). Overlaying layers $U$ and $D$ and the dispersion variance of $U$ over the sub-regions of the influential factors, $D_{i}$ is denoted as $\sigma^{2} U_{D, i}(i=1,2, \ldots, m)$; thus, the power of the determinant $\mathrm{D}=\left\{\mathrm{D}_{\mathrm{i}}\right\}$ to the transition performance $\mathrm{H}$ is specified in Equation (8).

$$
\mathrm{P}_{\mathrm{D}, \mathrm{U}}=1-\frac{1}{\mathrm{n} \sigma^{2} \mathrm{U}} \sum_{\mathrm{i}=1}^{\mathrm{m}}\left(\mathrm{n}_{\mathrm{D}, \mathrm{i}} \times \sigma^{2} \mathrm{U}_{\mathrm{D}, \mathrm{i}}\right)
$$

where $n_{D, i}$ denotes the number of resource-based cities in sub-regions with the influential factors $D_{i}$, and $\sigma^{2} U$ denotes the dispersion variance of $U$ in the entire region. $P_{D, U} \in[0,1]$. When $P_{D, U}=0$, this proves that the transition performance of resource-based cities is randomly distributed. The larger $\mathrm{P}_{\mathrm{D}, \mathrm{U}}$ is, the greater the impact of the influential factors on the transition performance.

In Step 4, based on the assessment of variations in the urban transition performance of resource-based cities and the mechanisms and strengths of influential factors, we discuss the measures for further promoting urban transition performance. 


\subsection{Data Collection}

Statistical data were predominantly obtained from the China City Statistical Yearbook $(2004,2013)$, Liaoning Statistical Yearbook (2004, 2013), Jilin Statistical Yearbook $(2004,2013)$, Heilongiiang Statistical Yearbook (2004, 2013) and China Statistical Yearbook for Regional Economics (2004, 2013). Travelling time was acquired from Google Maps. Basic urban vector data were obtained from the Institute of Earth System Science's data sharing platform (http:/ /www.geodata.cn) (Table 2).

Table 2. The data sources of indicators.

\begin{tabular}{cc}
\hline Indicators & Data Sources \\
\hline $\begin{array}{c}\mathrm{x}_{1}, \mathrm{x}_{2}, \mathrm{x}_{3}, \mathrm{x}_{5}, \mathrm{x}_{6}, \mathrm{x}_{7}, \mathrm{x}_{9}, \mathrm{x}_{11}, \mathrm{x}_{12}, \mathrm{x}_{13}, \mathrm{x}_{14}, \\
\mathrm{x}_{16}, \mathrm{x}_{20}, \mathrm{x}_{21}, \mathrm{x}_{22}, \mathrm{x}_{23}, \mathrm{x}_{24}, \mathrm{x}_{2}, \mathrm{x}_{4}, \mathrm{x}_{5}, \mathrm{x}_{7}\end{array}$ & China City Statistical Yearbook $(2004,2013)$ \\
\hline $\mathrm{x}_{15}, \mathrm{x}_{17}, \mathrm{x}_{18}, \mathrm{x}_{19}$ & $\begin{array}{r}\text { Liaoning Statistical Yearbook (2004, 2013), Jilin Statistical } \\
\text { Yearbook (2004, 2013), Heilongjiang Statistical Yearbook }(2004,2013)\end{array}$ \\
\hline $\mathrm{x}_{4}, \mathrm{x}_{8}, \mathrm{x}_{10}$ & China Statistical Yearbook for Regional Economics $(2004,2013)$ \\
\hline $\mathrm{x}_{3}$ & Google Maps \\
\hline
\end{tabular}

\section{Urban Transition Performance}

We calculated the performance of each city in Northeast China. The results of the urban transition performances of the 19 resource-based cities in Northeast China since 2003 are shown in Figure 2. The results show that the gap in transition performance among the resource-based cities is not huge. The difference between the best case (Liaoyuan) and the worst case (Heihe) is only 0.244 . This is mostly because the economic strength of resource-based cities in Northeast China is universally weak and is slowly developing. There are eight cities, including Liaoyuan and Songyuan, where the transition performance is higher than the average level for Northeast China. The three top-performing cities are Liaoyuan, Songyuan and Baishan; all of which are in Jilin province. They are then followed by Fushun, Huludao and Fuxin; all of which are in Liaoning province. The three worst-performing cities are Jixi, Yichun and Heihe; all are in Heilongjiang province. Overall, the transition performance of the resource-based cities in Jilin and Liaoning provinces is better than those in Heilongjiang province. The average transition performances levels of the cities in Liaoning, Jilin and Heilongiiang were 0.458, 0.491 and 0.381 , respectively. The reasons for the poor performance of the resource-based cities in Heilongjiang province are primarily as follows: the traffic conditions, location, economic environment and other factors are poor, and the lack of government policy support is also a contributing factor. Among the 69 cities designated as resource-exhausted cities, which therefore receive preferential policy support, only six cities are in Heilongjiang Province, but 14 cities are in Liaoning and Jilin Province. Furthermore, the resource-exhausted cities in Liaoning and Jilin Provinces were mostly designated in the first (2008) and second batches (2009), whereas those in Heilongjiang were mostly designated in the third batch (2012). Thus, the central government has supported the resource-based cities in Liaoning and Jilin Provinces for a longer period of time compared to those in Heilongjiang Province. Central government support includes the provision of a large amount of funding to support public infrastructure projects, eco-environmental restoration and the development of new industries; it also helps to solve enterprise problems with historical causes and other problems in resource-exhausted cities.

The trends of economic, social and eco-environmental transition performance are shown in Figure 3. Economic transition performance is similar to overall urban transition performance. Liaoyuan, Shuangyashan and Songyuan perform the best, followed by Fuxin, Anshan and Benxi, but Hegang, Qitaihe, Daqing and Heihe perform poorly. Daqing's economic transition scored poorly compared with its urban transition performance. The economic structure of Daqing is highly dependent on petroleum, and as a result, the city's transition to new industries and tertiary industries is difficult, while the industrial structure is adjusting slowly. In terms of social transition, the three top-performing cities are Songyuan, Liaoyuan, Daqing; Shuangyashan, Jixi, Yichun and other coal and forestry cities 
perform poorly. There is a correlation between economic strength and social transition performance. The petroleum cities usually have strong economic strength, while the economic strength in coal and forestry cities was weak. This is because economic strength has provided a solid economic foundation for social development, including infrastructure improvements, rising living standards, education, healthcare and the development of other public services. Hegang, Mudanjiang and Huludao are the best performers in terms of eco-environmental transition, but Anshan and Fuxin perform poorly. The difference in the eco-environmental transition among the resource-based cities is not significant; and there are 10 cities whose eco-environmental transition is better than the average for Northeast China. From the results above, we could find that economic, social and environmental sustainability are somewhat competing goals. Taking Fuxin, the first experimental economic transition resource-based city, as an example, we could find that the economic transition performance is good, while the social and environmental transition performance is worse, especially the environmental transition, ranking last. The good economic transition performance gains are at the cost of ecological environment deterioration. Therefore, the urban transition should not only focus on the economic transition, but also value the social and environmental transition.

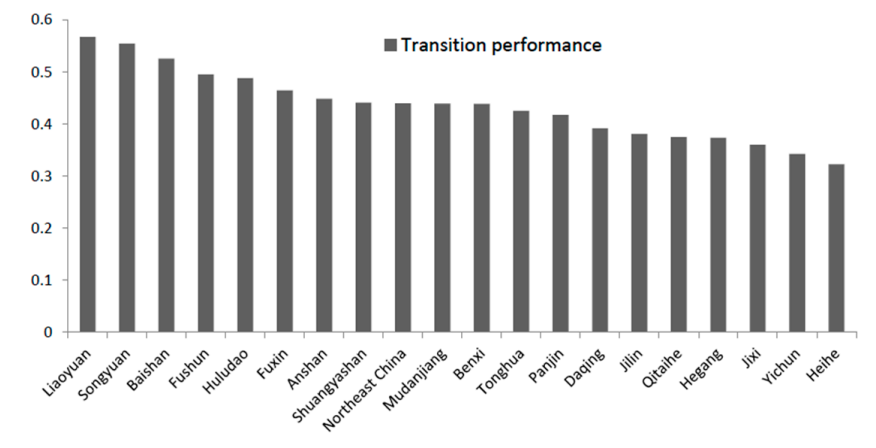

Figure 2. The value of the transition performance of resource-based cities in Northeast China.

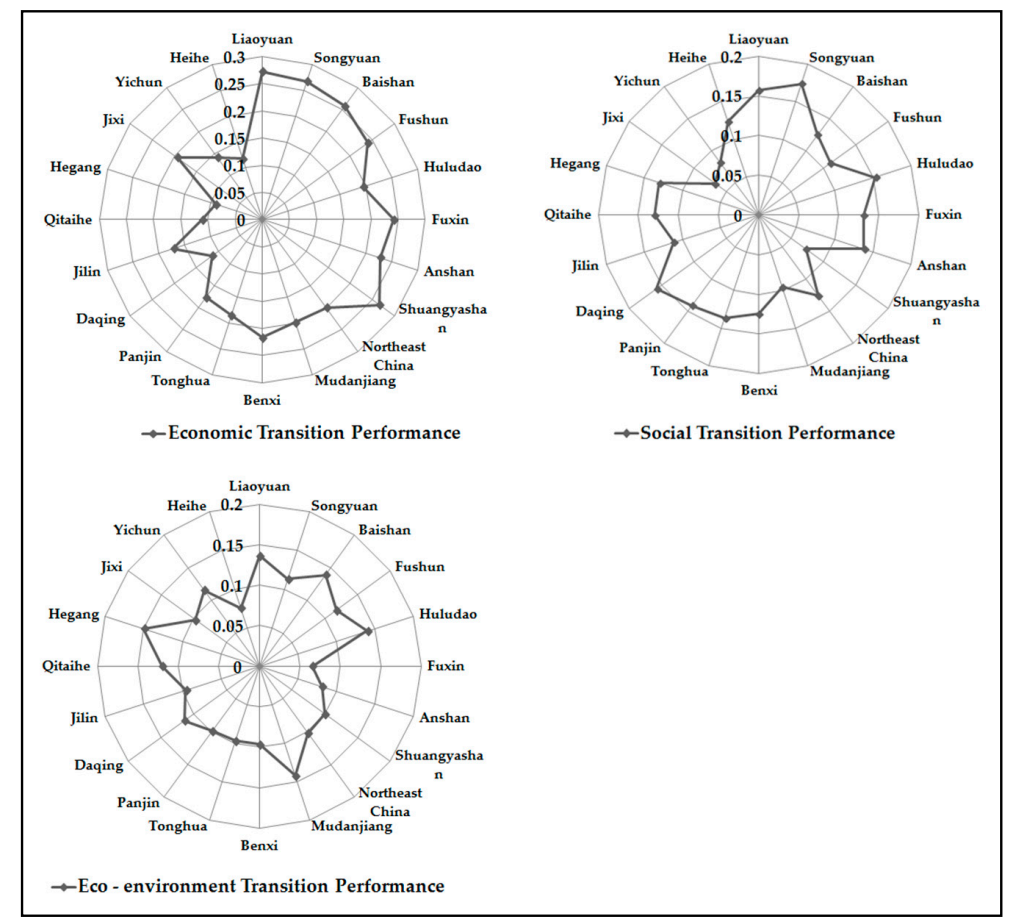

Figure 3. Economic, social and eco-environmental transition performance of the resource-based cities in Northeast China. 
Based on the types of resources on which they are based, the resource-based cities are divided into five types (multi-resource, petroleum, metal, coal and forestry cities), and the mean values of the urban transition performance of each type are calculated (Table 3). We determined that the best transition performance is found in multi-resource-based, followed by petroleum-, mental-, coal- and forestry-based cities. Multi-resource and metal-based cities perform better in economic transitions. The mineral resources of Tonghua, Huludao and Liaoyuan were diverse, and thus, these cities' dependence on a single mineral resource was relatively low. Originally, Liaoyuan relied on coal, limestone for cement and building stone; Tonghua relied on iron ore, gold ore and coal; and Huludao relied on coal and nonferrous metals. Now, the coal in Liaoyuan has been depleted; the city must cultivate alternative industries, and Liaoyuan has established a new industry structure based on new materials, health and traditional industries. Furthermore, the medicine, food and machinery manufacturing industries have become the leading industries in Tonghua, and equipment manufacturing and cultural tourism are becoming leading industries in Huludao. Therefore, the urban transitions of multi-resource cities are easier, and their transition performance is better.

Table 3. Average value of urban transition performance for different types of resource-based cities.

\begin{tabular}{ccccc}
\hline Type of Mineral Resources & $\begin{array}{c}\text { Urban } \\
\text { Transition }\end{array}$ & $\begin{array}{c}\text { Economic } \\
\text { Transition }\end{array}$ & $\begin{array}{c}\text { Social } \\
\text { Transition }\end{array}$ & $\begin{array}{c}\text { Eco-Environmental } \\
\text { Transition }\end{array}$ \\
\hline Multi-resource & 0.4937 & 0.2173 & 0.1490 & 0.1245 \\
Petroleum & 0.4544 & 0.1857 & 0.1574 & 0.1089 \\
Metal & 0.4435 & 0.2225 & 0.1315 & 0.0894 \\
Coal & 0.4183 & 0.1907 & 0.1070 & 0.1084 \\
Forestry & 0.4022 & 0.1775 & 0.1073 & 0.1138 \\
\hline
\end{tabular}

The petroleum cities perform well in terms of social transition, but poorly in terms of economic transition. Because of these cities' robust economic strength and abundant oil, their quality of life, employment opportunities and other social issues improved more than in other cities. However, their excessive dependence on oil results in a single industrial structure. With the petroleum and petrochemical industry accounting for a high proportion of their economies, their output is dominated by the primary processing of petroleum resources, a short industrial chain and a lack of product competitiveness [44]; thus, their economic transition performance is poor.

Metal-based cities exhibit strong economic transitions, and this has a significant relationship with the adjustment of their industrial structures. Benxi accelerated the development of its biomedical industry; its total sales of 30 billion Yuan accounted for $28.6 \%$ of its total GDP. Anshan developed fine steel, deep processed steel and new materials for the magnesite industry. However, metal-based cities typically exhibit the worst eco-environmental transitions. Opencast operations produce large amounts of dust, and steel smelting consumes large amounts of energy and water and produces large quantities of pollutants, all of which have adverse effects on environmental improvement. The transition performance of coal cities is poor, especially among the four lowest-ranked coal cities in Heilongjiang province. This is primarily because these cities typically focus on coal mining and the primary processing of coal as their leading industries, but the sustained low price of coal products has resulted in a high ratio of liabilities and a high level of unemployment. Simultaneously, coal mining and processing cause serious water, land and air pollution $[45,46]$. The urban transition performance of forestry-based cities is the worst because their locations are typically very remote, and they are therefore disadvantaged in attracting new industries. In addition, excessive logging during the planned economy period resulted in the gradual depletion of their forest resources. More recently, the Natural Forest Protection Project, initiated in 2000 by the central government, places serious restrictions on the deforestation of natural forests. The aim of this project was to protect natural forests by changing the main economic function of forestry-based cities. However, the program has put these cities' logging corporations in a very difficult situation and created large numbers of unemployed workers, all of which contributes to their poor urban transition performance. 


\section{Influential Factors}

\subsection{Selection of Influential Factors}

The transition of resource-based cities is complex, affected not only by the cities' own conditions, but also by the external environment [47]. We selected eight indicators based on various characteristics of these cities. Exploitable resources are the basis of resource-based cities' development. The resource-based cities were divided into four types-growing, mature, recessionary and recovered-based on the support capabilities of the resources as defined in the "National Resource Sustainable Urban Development Plan (2013-2020)". "Growing" refers to cities that have great potential for an upswing in the supply and exploitation of their resources. "Mature" resource-based cities have high resource guarantee abilities, and their resource exploitation is stable. In "recessionary" resource-based cities, resources are becoming exhausted; while "recovered" refers to cities that have essentially ended their resource dependence. We assigned values of 4, 3, 2 and 1 to the four types of cities. From the location and transport perspective, we selected location advantage and road density. Location advantage is determined by the distance to the provincial capital, and road density is calculated by the ratio of total highway length to the region's total area. The accumulated investment in fixed assets and the proportion of employed persons in the urban area since 2003 are used to represent the capital input and labor input factors. From a policy perspective, cities that have been chosen to join the national experimental resource-based cities program, a key government policy supporting resource-based cities, are given a value of four. Cities designated in the first batch of resource-exhausted cities in 2008 are also given the assigned value of four. Next, the second batch of resource-exhausted cities (designated in 2009) was assigned the value of three, and the third batch of resource-exhausted cities (designated in 2011) was assigned the value of two. Other cities were assigned the value of one, as shown in Table 4. Finally, we selected each city's level of sustainable development and urban scale to represent its urban development basis.

Table 4. Assigned values of policies supporting resource-based cities in Northeast China.

\begin{tabular}{|c|c|c|}
\hline Urban & Supporting Policies & Assigned Value \\
\hline $\begin{array}{l}\text { Anshan, Benxi, Songyuan, } \\
\text { Jixi, Mudanjiang }\end{array}$ & Policy support for general resource-based cities & 1 \\
\hline Hegang, Shuangyashan & $\begin{array}{l}\text { Policy support for third batch of } \\
\text { resource-exhausted cities }\end{array}$ & 2 \\
\hline Tonghua (Erdaojiang district) & $\begin{array}{l}\text { Policy support for third batch of } \\
\text { resource-exhausted districts }\end{array}$ & 2 \\
\hline Fushun, Qitaihe & $\begin{array}{l}\text { Policy support for second batch of } \\
\text { resource-exhausted cities }\end{array}$ & 3 \\
\hline $\begin{array}{l}\text { Jilin (Shulan), } \\
\text { Heihe (Wudalianchi) }\end{array}$ & $\begin{array}{l}\text { Policy support for second batch of } \\
\text { resource-exhausted counties }\end{array}$ & 3 \\
\hline Huludao (Nanpiao district) & $\begin{array}{l}\text { Policy support for second batch of } \\
\text { resource-exhausted districts }\end{array}$ & 3 \\
\hline Daqing & $\begin{array}{l}\text { Policy support for experimental resource-based } \\
\text { cities for economic transition }\end{array}$ & 4 \\
\hline $\begin{array}{l}\text { Fuxin, Panjin, Liaoyuan, } \\
\text { Baishan, Yichun }\end{array}$ & $\begin{array}{l}\text { Policy support for experimental resource-based } \\
\text { cities for economic transition and first batch of } \\
\text { resource-exhausted cities }\end{array}$ & 4 \\
\hline
\end{tabular}

\subsection{Detecting the Influential Factors in Urban Transition Performance}

We categorized the continuous influential factors using the Jenks method in ArcGIS because categorical data are better than continuous data for the processing of geographic detector. The results are shown in Figure 4. 


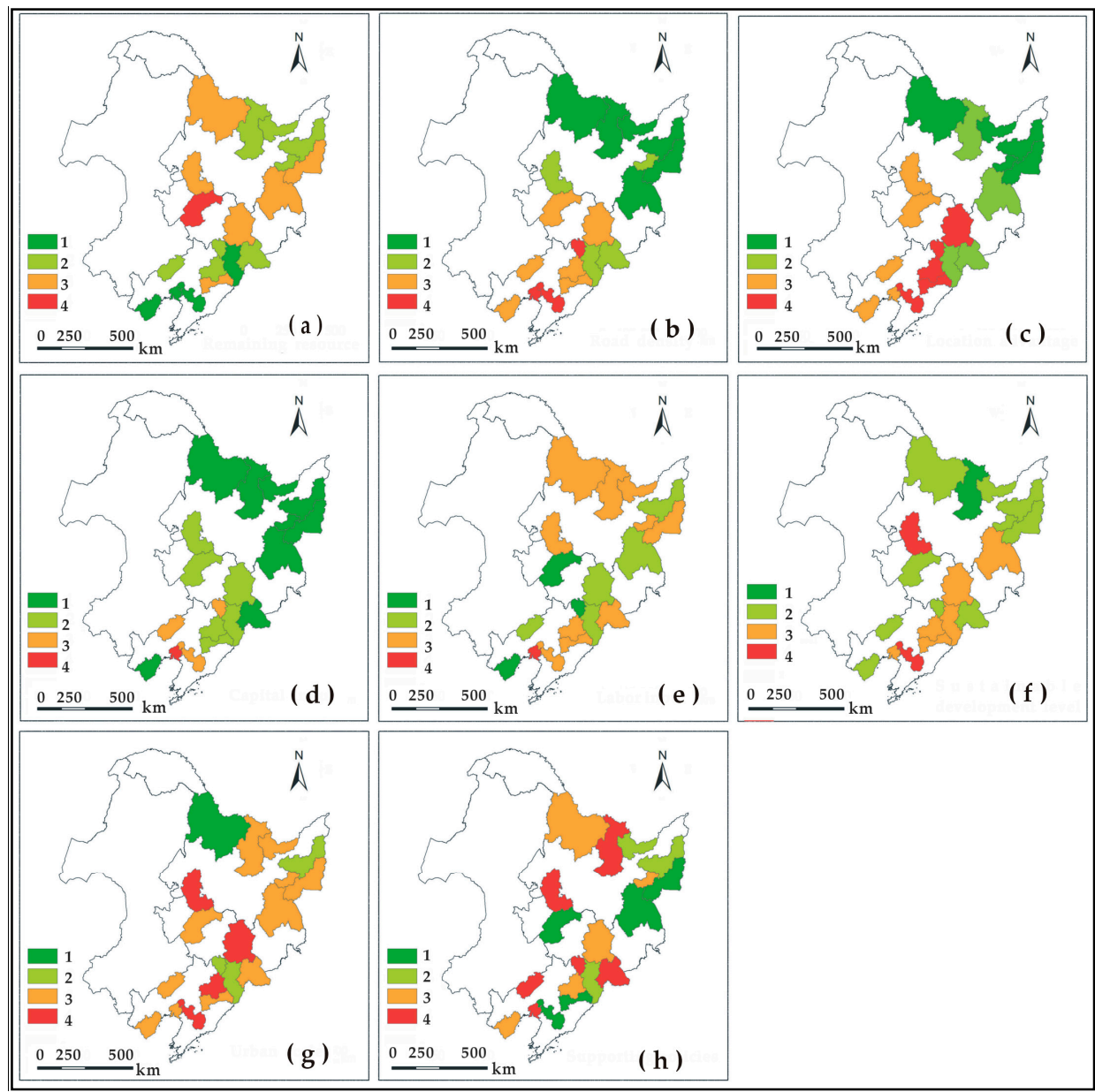

Figure 4. Spatial distribution of classified influential factors: (a) Remaining resources; (b) Road density; (c) Location advantage; (d) Capital input; (e) Labor input; (f) Sustainable development level; (g) Urban scale; (h) Supporting policies.

We calculated the power of the influential factors over the cities' transition performance $\left(\mathrm{P}_{\mathrm{D}, \mathrm{U}}\right)$ using the Factor Detector and analyzed the effects of the different influential factors on the urban transition performance of resource-based cities in Northeast China (Table 5). The values of $P_{D, U}$ are larger in every other province than those in Northeast China. This is primarily because the environments of the transition performance are different among the three provinces: every province is an independent administrative unit, and the mechanism and strengths affected by the potential determinants are different.

Table 5. Influential factors on the urban transition performance.

\begin{tabular}{ccccc}
\hline \multirow{2}{*}{ Detection Indicator } & \multicolumn{3}{c}{$\mathbf{P}_{\mathbf{D}, \mathbf{U}}$} \\
\cline { 2 - 5 } & Northeast China & Liaoning & Jilin & Heilongjiang \\
\hline Remaining resources $\left(\mathrm{X}_{1}\right)$ & 0.179 & 0.558 & 0.998 & 0.148 \\
Road density $\left(\mathrm{X}_{2}\right)$ & 0.381 & 0.419 & 0.453 & 0.324 \\
Location advantage $\left(\mathrm{X}_{3}\right)$ & 0.289 & 0.243 & 0.733 & 0.572 \\
Capital input $\left(\mathrm{X}_{4}\right)$ & 0.343 & 0.953 & 0.680 & 0.393 \\
Labor input $\left(\mathrm{X}_{5}\right)$ & 0.157 & 0.395 & 0.347 & 0.264 \\
Sustainable development level $\left(\mathrm{X}_{6}\right)$ & 0.173 & 0.640 & 0.222 & 0.609 \\
Urban scale $\left(\mathrm{X}_{7}\right)$ & 0.191 & 0.205 & 0.269 & 0.648 \\
Supporting policies $\left(\mathrm{X}_{8}\right)$ & 0.103 & 0.373 & 0.998 & 0.751 \\
\hline
\end{tabular}


In Northeast China, capital input $\left(X_{4}\right)$, road density $\left(X_{2}\right)$ and location advantage $\left(X_{3}\right)$ have the highest influence on urban transition performance. The cost of an urban transition is massive; but funds are limited, and it is difficult to secure financing. Therefore, urban transition funds become the most prominent limitation in resource-based cities. The cultivation of new industries, the protection and restoration of the eco-environment and the construction of infrastructure all require massive capital input, where government funding has typically played a major guiding and driving role. Therefore, investment in fixed assets has the greatest influence on urban transition performance. Resource-based cities are often dependent on a particular natural resource, but the distribution of natural resources and the economic, social and transportation factors that influence urban development are often not fully coupled, resulting in resource-based cities that tend to remain isolated from the economic center of the region [48]. In addition, remote locations and poor transportation retard urban transitions. Cities in more central locations tend to perform better in urban transitions. For example, cities in the central Jilin and Liaoning provinces and those around the Harbin-Dalian railway perform well in urban transitions, whereas cities in remote areas of Heilongjiang province perform poorly.

Urban scale $\left(X_{7}\right)$, remaining resources $\left(X_{1}\right)$ and sustainable development level $\left(X_{6}\right)$ also have a major influence on urban transition performance. Regarding urban scale, for cities with non-agricultural populations below 200,000 in urban areas, the average urban transition performance score is 0.360 . For cities with populations of 200,000 to 500,000 , the score is 0.448 . For cities with populations of 500,000 to one million, the score is 0.425 . For cities with populations over one million, the score is 0.446 . We found that a small city (Heihe) has the worst transition performance, primarily due to its remote location and poor urban development environment, whereas larger cities perform better. Regarding remaining resources, the mean values of the transition performance scores in growing, mature, recessionary and recovered cities are $0.554,0.389,0.448$ and 0.445 , respectively. The growing cities are ranked first, primarily due to the upswing in resource exploitation and its high economic development potential, which makes their urban transition easier. The recession cities are ranked second. The natural resources in these cities have been exhausted; livelihood issues are acute; and the eco-environment has been stressed; all of which complicate efforts for urban transition. The mature cities exhibited the worst performance. The resource exploitation in these cities is stable, and they have developed strong resource dependence. Thus, these mature resource-based cities lack the motivation to develop new industries and improve their eco-environments. Supporting policies $\left(\mathrm{X}_{8}\right)$ and labor input $\left(\mathrm{X}_{5}\right)$ have a small effect on differentiating urban transition performance.

At the provincial level, capital input, sustainable development level and remaining resources have the greatest impact on urban transitions in Liaoning province: capital input has a positive correlation with urban transition, but sustainable development level and remaining resources have a negative correlation. Supporting policies, remaining resources and location advantage have the greatest and most positive impacts on urban transitions in Jilin province. Liaoyuan and Baishan, which are experimental resource-based cities undergoing economic transitions, and Songyuan, which is in a good location and is resource rich, all perform well in terms of urban transition. Supporting policies, urban scale and sustainable development have the greatest impacts on urban transitions in Heilongiiang province, with urban scale and sustainable development levels having a positive correlation and supporting policies having a negative correlation, primarily because Yichun and Daqing, experimental resource-based cities undergoing economic transition, perform poorly, especially in terms of economic transition.

\section{Policy Implications}

Based on our findings, the following policy implications are offered to improve the transition performance of resource-based cities in Northeast China. First, the government should establish a sound long-term assistance mechanism for the sustainable development of resource-based cities. Capital input has the strongest effect on urban transition, but the ability to accumulate capital and the regulation and management of funds are limited in resource-based cities. Therefore, the national 
and provincial governments should formulate policies and provide financial support to guide and promote the development of resource-based cities. The funding support by the national government should target construction of energy, communications and water conservancy and other infrastructure projects; upgrading industry and agriculture.

Second, the government should strengthen the construction of transportation infrastructure, enhance trading and attract foreign investment. This is especially important and challenging for forestry-based cities and coal-based cities in Heilongjiang province, which suffer from poor locations. These cities should focus on the construction of transportation infrastructure to create better connections with regional centers.

Third, policies from higher levels of government should become more sensitive to local contexts. At a minimum, they need to consider different types of resource-based cities, as the one-size-fits-all approach does not help solve all of the cities' key problems [49]. For instance, context-specific programs should pay more attention to the economic transitions of petroleum-based cities, to the economic and social transitions of coal- and forestry-based cities and to the eco-environmental transitions of metal cities. Policies regarding urban transition involve various departments within local and provincial governments; therefore, the processes of policymaking and implementation need to be better coordinated. Taking Yichun as an example, there is potential for the high-tech food and drug industries to become strong alternative industries, and therefore, the provincial government should escalate its preferential policies to facilitate relevant projects and industrial chains.

Finally, when the government evaluates the cities' performance on urban transitions, it should not narrowly focus on input-output, but should fully consider location conditions, the external development environment, the level of sustainable development and other factors.

\section{Summary and Conclusions}

In this study, we developed a systematic method to evaluate the transition of resource-based cities based on economic, social and eco-environmental factors and used the system to analyze the transition performance of 19 resource-based cities in Northeast China beginning in 2003. We also analyzed the factors that influence urban transition performance. Two conclusions can be drawn.

First, Liaoyuan, Songyuan and Baishan in Jilin province performed better in terms of urban transition; Jixi, Yichun and Heihe in Heilongjiang province performed poorly. The resource-based cities in Liaoning and Jilin province showed better performance than those in Heilongjiang province. Multi-resource and petroleum resource-based cities performed well, but coal- and forestry-based cities performed poorly. Economic transition has the largest effect on urban transition; the petroleum cities performed better in terms of social transition; and the difference in the eco-environmental transition among the cities is not significant.

Second, in Northeast China, capital input, road density and location advantage have the greatest effects on urban transition performance, followed by urban scale, remaining resources and the level of sustainable development; supporting policies and labor input have small effects. Supporting policies have a small effect on urban transition performance, which suggests that this factor is not as influential as the other factors. However, the effect of supporting policies in some provinces is high, especially in Jilin and Heilongiiang Province. Because the province is a relatively independent administrative unit, there are remarkable differences in levels of development; thus, the mechanisms and strengths of influential factors are different in different provinces.

The experiences from our article have important theoretical and practical significance, in terms of developing new methods to assess urban transition performance, exploring a variety of mechanisms to urban transition and providing guidance for further efforts. However, our research has several limitations that should be addressed in the future. First, because of problems with the acquisition of the data, the index system is not perfect. Therefore, improvement of the index system will be the focus of our next study. Moreover, this study focused only on Northeast China. In the future, we will compare the Northeast with resource-based cities in other areas, and therefore, the results will be national 
rather than regional. Finally, we only analyzed the starting point (2003) and the ending point (2012). The limitation of this approach is that we could only evaluate the results of urban transition. In the future, we will develop a method to evaluate annual changes, which will give us more insights into the process of urban transition.

Acknowledgments: This work was supported by the National Natural Science Foundation of China (41571152, 41201160, 41201159, 71541021), the Knowledge Innovation Program of the Chinese Academy of Sciences (KSZD-EW-Z-021), the National Key Technology Program (2008BAH31B06), and the Key Consulting Program of the Chinese Academy of Sciences (Y02015005).

Author Contributions: All of the authors made contributions to the work in this paper. Juntao Tan and Pingyu Zhang designed the research. Juntao Tan wrote the paper articles and Pingyu Zhang checked it. Kevin Lo modified the article and improved language. Jing Li and Shiwei Liu contributed data collecting and results analyzing.

Conflicts of Interest: The authors declare no conflict of interest.

\section{References}

1. Zhang, W.Z.; Yu, J.H.; Wang, D. Study on the development path and pattern of substituted industry in Resource-based cities. Bull. Chin. Acad. Sci. 2011, 26, 134-141.

2. Long, R.; Chen, H.; Li, H.; Wang, F. Selecting alternative industries for Chinese resource cities based on intra-and inter-regional comparative advantages. Energy Policy 2013, 57, 82-88. [CrossRef]

3. Li, Q.; Zhang, W.Z.; Wang, D. Current status, challenges and policy recommendations regarding the sustainable development of mining areas in China. J. Resour. Ecol. 2014, 5, 42-52.

4. Li, H.; Long, R.; Chen, H. Economic transition policies in Chinese resource-based cities: An overview of government efforts. Energy Policy 2013, 55, 251-260. [CrossRef]

5. Frantzeskaki, N.; de Haan, H. Transitions: Two steps from theory to policy. Futures 2009, 41, 593-606. [CrossRef]

6. Nevens, F.; Frantzeskaki, N.; Gorissen, L.; Loorbach, D. Urban Transition Labs: Co-creating transformative action for sustainable cities. J. Clean Prod. 2013, 50, 111-122. [CrossRef]

7. Wei, H.K. Strategy of Urban Transformation in China. J. Urban Reg. Plan 2011, 1, 2-19.

8. McCormick, K.; Anderberg, S.; Coenen, L.; Neij, L. Advancing sustainable urban transformation. J. Clean Prod. 2013, 50, 1-11. [CrossRef]

9. Shepotylo, O. Cities in transition. Comp. Econ. Stud. 2012, 54, 661-688. [CrossRef]

10. Sýkora, L.; Bouzarovski, S. Multiple transformations conceptualizing the post-communist urban transition. Urban Stud. 2012, 49, 43-60. [CrossRef]

11. Innis, H.A. The Cod Fisheries: The History of an International Economy; Yale University Press: New Haven, TN, Canada, 1940.

12. Bradbury, J.H. Towards an alternative theory of resource-based town development in Canada. J. Econ. Geogr. 1979, 147-166. [CrossRef]

13. Houghton, D.S. Long-distance commuting: A new approach to mining in Australia. J. Econ. Geogr. 1993, 159, 281-290. [CrossRef]

14. Dong, S.; Li, Z.; Li, B.; Mei, X. Problems and strategies of industrial transformation of China's Resource-based cities. China Popul. Resour. Environ. 2007, 17, 12-17.

15. Hajkowicz, S.A.; Heyenga, S.; Moffat, K. The relationship between mining and socio-economic well being in Australia's regions. Resour. Policy 2011, 36, 30-38. [CrossRef]

16. Sun, W.; Li, Y.; Wang, D.; Fan, J. The efficiencies and their changes of China's resources-based cities employing DEA and Malmquist Index Models. J. Geogr. Sci. 2012, 22, 509-520. [CrossRef]

17. Shen, L.; Andrews-Speed, P. Economic analysis of reform policies for small coal mines in China. Resour. Policy 2001, 27, 247-254. [CrossRef]

18. Matshediso, I.B. A review of mineral development and investment policies of Botswana. Resour. Policy 2005, 30, 203-207. [CrossRef]

19. Liu, Z.; Zhou, W.S.; Yao, H. Progress of studies abroad on development and transition of Resource-based Cities. China Popul. Resour. Environ. 2011, 21, 161-168. 
20. Azapagic, A. Developing a framework for sustainable development indicators for the mining and minerals industry. J. Clean Prod. 2004, 12, 639-662. [CrossRef]

21. Chen, R.H.; Lin, Y.; Tseng, M.L. Multicriteria analysis of sustainable development indicators in the construction minerals industry in China. Resour. Policy 2015, 46, 123-133. [CrossRef]

22. Yu, J.; Zhang, Z.; Zhou, Y. The sustainability of China's major mining cities. Resour. Policy 2008, 33, 12-22. [CrossRef]

23. Wang, L.C.; Zhang, Y.F. Sustainable development of the mineral-resources-based cities in arid areas. Arid Land Geogr. 2004, 27, 426-430.

24. Dong, F.; Tan, Q.M.; Zhou, D.Q.; Long, R.; Zhu, J. An Evaluation of Resource-Based City's Sustainable Development Level: A Case Study on Daqing City in Heilongjiang Province. Resour. Sci. 2010, 32, 1584-1588.

25. Guo, C.Z.; Luo, L.L.; Ye, M. Empirical Analysis of Factors Influencing the Sustainable Development of Resource-based Cities. China Popul. Resour. Environ. 2014, 24, 81-89.

26. Yu, J.H.; Zhang, W.Z.; Wang, D.; Li, Q. The effect of Resource-exhausted city transformation. Resour. Sci. 2013, 35, 1812-1820.

27. Yu, J.H.; Zhang, W.Z.; Wang, D. Evaluation of the China's Resource-exhausted cities' transformation effect. J. Nat. Resour. 2011, 26, 11-21.

28. Pälli, P.; Lehtinen, E. Making objectives common in performance appraisal interviews. Lang. Commun. 2014, 39, 92-108. [CrossRef]

29. Pettijohn, C.E.; Pettijohn, L.S.; d'Amico, M. Characteristics of performance appraisals and their impact on sales force satisfaction. Hum. Resour. Dev. Quart. 2001, 12, 127-146. [CrossRef]

30. Li, R.; Song, Y.; Li, Y.; Yu, T. The identification of transition stages and causes of resource-based cities in Jilin Province. Sci. Geogr. Sin. 2016, 36, 90-98.

31. Zhang, P.Y. Regional Development Report of Northeast China 2008; Science Press: Beijing, China, 2008.

32. Singh, R.K.; Murty, H.R.; Gupta, S.K.; Dikshit, A.K. An overview of sustainability assessment methodologies. Ecol. Indic. 2009, 9, 189-212. [CrossRef]

33. Newman, P.; Kenworthy, J. Sustainability and Cities: Overcoming Automobile Dependence; Island Press: Washington, DC, USA, 1999.

34. Zavadskas, E.K.; Kaklauskas, A.; Saparauskas, J. Sustainable urban development and web-based multiple criteria analysis. Found. Civ. Environ. Eng. 2005, 6, 217-226.

35. Michael, F.L.; Noor, Z.Z.; Figueroa, M.J. Review of urban sustainability indicators assessment-Case study between Asian countries. Habitat Int. 2014, 44, 491-500. [CrossRef]

36. Guan, D.; Gao, W.; Su, W.; Li, H.; Hokao, K. Modeling and dynamic assessment of urban economy-resource-environment system with a coupled system dynamics-geographic information system model. Ecol. Indic. 2011, 11, 1333-1344. [CrossRef]

37. Wang, Q.; Yuan, X.; Cheng, X.; Mu, R.; Zuo, J. Coordinated development of energy, economy and environment subsystems-A case study. Ecol. Indic. 2014, 46, 514-523. [CrossRef]

38. Zou, Z.H.; Yi, Y.; Sun, J.N. Entropy method for determination of weight of evaluating indicators in fuzzy synthetic evaluation for water quality assessment. J. Environ. Sci. 2006, 18, 1020-1023. [CrossRef]

39. Li, Y.; Li, Y.; Zhou, Y.; Shi, Y.; Zhu, X. Investigation of a coupling model of coordination between urbanization and the environment. J. Environ. Manag. 2012, 98, 127-133. [CrossRef] [PubMed]

40. Wu, K.Y.; Jin, J.L. Attribute recognition method of regional ecological security evaluation based on combined weight on principle of relative entropy. Sci. Geogr. Sin. 2008, 28, 754-758.

41. Wang, J.F.; Li, X.H.; Christakos, G.; Liao, Y.; Zhang, T.; Gu, X.; Ying, X. Geographical detectors-based health risk assessment and its application in the Neural Tube defects study of the Heshun Region, China. Int. J. Geogr. Inform. Sci. 2010, 24, 107-127. [CrossRef]

42. Hu, Y.; Wang, J.; Li, X.; Zhu, J. Geographical detector-based risk assessment of the under-five mortality in the 2008 Wenchuan Earthquake, China. PLoS ONE 2011, 6, 1-8. [CrossRef] [PubMed]

43. Ding, Y.; Cai, J.M.; Ren, Z.P.; Yang, Z. Spatial disparities of economic growth rate of China's National-level ETDZs and their determinants based on geographical detector analysis. Prog. Geogr. 2014, 33, 657-666.

44. Liu, Y.G. Studies on the adjustment of the industrial structure of resource type cities in the Northeast Area. Econ. Geogr. 2000, 20, 26-29.

45. Hao, C.B.; Jiang, Y.; Xiao, F.K. Strategy Research for Industrial transformation of coal cities in Heilongjiang Province. Coal Technol. 2006, 25, 1-3. 
46. Jiang, J.Q.; Ma, Y.J.; Tong, L.J. Study on the question of sustainable development of Coal-Mining cities in the Northeast China. Sci. Geogr. Sin. 2000, 20, 241-245.

47. Zhang, P.Y. On the strategic problem and policies for the economic transformation of Fuxin city. Min. Res. Dev. 2005, 25, 1-5.

48. Sun, W.; Li, S.H. Quantifying location condition of resources-exhausted cities in China. Acta Geogr. Sin. 2013, 68, 199-208.

49. Yu, C.; de Jong, M.; Cheng, B. Getting depleted resource-based cities back on their feet again-The example of Yichun in China. J. Clean Prod. 2016, 134, 42-50. [CrossRef] article distributed under the terms and conditions of the Creative Commons Attribution (CC-BY) license (http://creativecommons.org/licenses/by/4.0/). 